
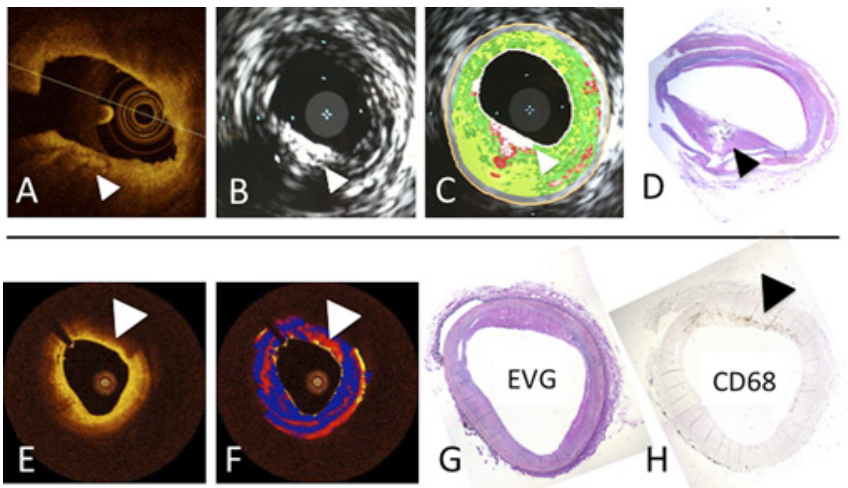

Abstract 023 Figure 2

\section{VALIDATION OF TISSUE CHARACTERISATION AND VULNERABLE PLAQUE CLASSIFICATION USING VIRTUAL HISTOLOGY IVUS (VH-IVUS) AGAINST HUMAN POST- MORTEM HISTOLOGY}

doi:10.1136/heartjnl-2012-301877b.24

${ }^{1} \mathrm{D}$ R Obaid, ${ }^{* 1} \mathrm{P}$ A Calvert, ${ }^{2} \mathrm{M}$ Goddard, ${ }^{1} \mathrm{M}$ R Bennett. ${ }^{1}$ University of Cambridge, UK; ${ }^{2}$ Papworth NHS Foundation Trust Hospital, UK

Introduction VH-IVUS is increasingly used in clinical trials to classify vulnerable thin-capped fibroatheroma (TCFA). However, VH-IVUS has not been validated for classifying coronary plaque against the gold standard of human post-mortem histology.

Methods Ten human coronary arteries were obtained at postmortem. VH-IVUS examination was performed in a pressureperfused system. The arteries were then fixed, stained and sectioned giving 72 co-registered $400 \mu \mathrm{m}$ segments. Slides from each segment were examined by a histopathologist to determine the presence of calcification, necrotic core and to classify any plaque present. A fibroatheroma was considered a TCFA if fibrous cap thickness was $<65 \mu \mathrm{m}$. VH-IVUS analysis was performed on each segment to compare tissue characterisation and plaque classification by an operator blinded to the histology. To explore a possible link between VH-IVUS detection of calcification and necrotic core artefact we also performed VH-IVUS of coronary segments in 20 patients preand immediately post-stenting to determine if there was a relationship between increasing calcium (simulated by stent struts) and necrotic core.

Results VH-IVUS was excellent at determining the presence of atherosclerotic plaque (sensitivity-100\%, specificity-93\%) and calci-
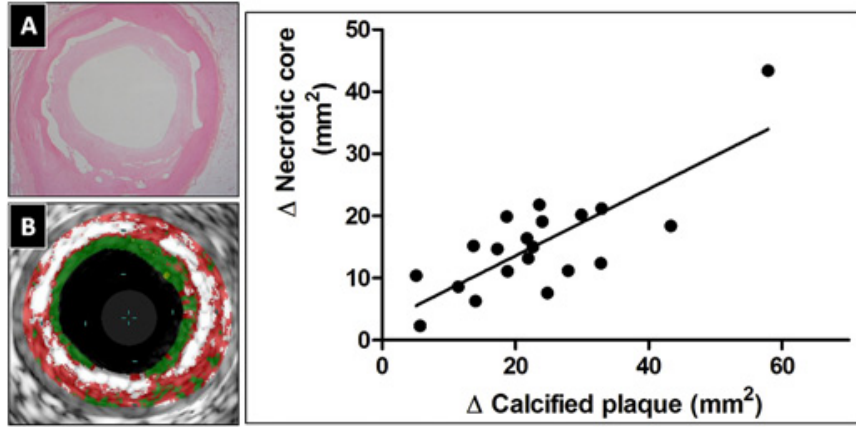

Abstract 024 Figure 1 (A) Post-mortem histology demonstrating presence of calcification and necrotic core with co-registered VH-IVUS (B) (necrotic core $=$ red, calcium $=$ white). fication (sensitivity-96\%, specificity-90\%) (Abstract 024 figure 1) Necrotic core was detected with a sensitivity of $100 \%$ but a specificity of $40 \%$. For classification of a fibroatheroma by VH-IVUS (confluent $\mathrm{NC}>10 \%$ of plaque area for three consecutive frames) sensitivity was $87 \%$ and specificity- $74 \%$. Of the 24 segments wrongly attributed to contain necrotic core by VH-IVUS, $92 \%$ also contained calcium ( $67 \%$ contained $>10 \%$ calcium). Stent struts are mistaken by VH-IVUS as calcification, surrounded by necrotic core not present on histology (Abstract 024 figure 2). Analysis of arterial segments pre- and post-stenting showed a linear correlation between increasing calcium (stent struts) with increases in necrotic core $\left(r^{2}=0.61\right)$ suggesting some necrotic core surrounding calcium maybe artefact. VH-IVUS distinguished TCFA (fibroatheroma with core in contact with lumen) with sensitivity-71\% and specificity$74 \%$. As $65 \mu \mathrm{m}$ is beyond the spatial resolution of VH-IVUS we repeated the analysis with caps $<200 \mu \mathrm{m}$ considered thin and the sensitivity of VH-IVUS to detect TCFA rose to $80 \%$, specificity- $76 \%$ (Abstract 024 table 1).

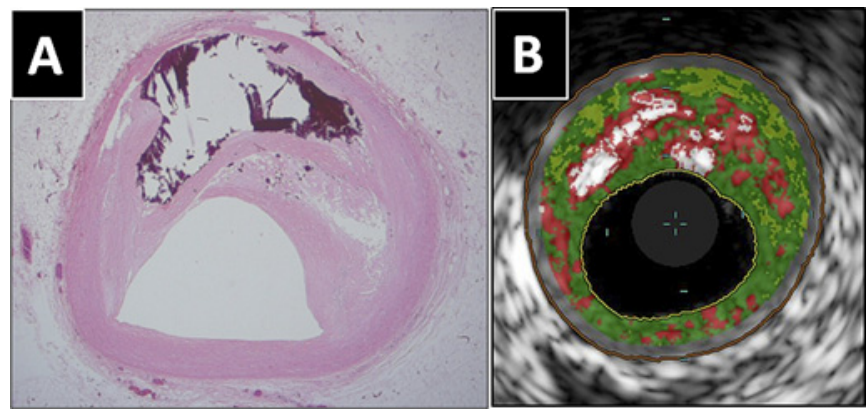

Abstract 024 Figure 2 Left : (A) Post-mortem histology demonstrated coronary segment with stent struts but no significant necrotic core. (B) Co-registered VH-IVUS image showing stent struts mistaken for calcium with necrotic core artefact. Right: Linear correlation between increase in calcified plaque and increase in necrotic core in coronary segments pre- and post-stenting.

Abstract 024 Table 1

\begin{tabular}{lc}
\hline Histology defined plaque & Correctly classified by VH-IVUS \\
\hline All Fibroatheroma & $26 / 30(87 \%)$ \\
Calcified Fibroatheroma & $18 / 26(69 \%)$ \\
Fibrocalcific & $9 / 24(38 \%)$ \\
All TCFA $(\operatorname{cap}<65 \mu \mathrm{m})$ & $5 / 7(71 \%)$ \\
Calcified TCFA $(\operatorname{cap}<65 \mu \mathrm{m})$ & $3 / 6(50 \%)$ \\
All TCFA $(\operatorname{cap}<200 \mu \mathrm{m})$ & $8 / 10(80 \%)$ \\
\hline
\end{tabular}

Conclusion In comparison with histology, VH-IVUS reliably discriminated calcified plaque and detected necrotic core (classifying fibroatheromas) with good sensitivity. However, the specificity to detect necrotic core dropped in the presence of dense calcification due to necrotic core artefact. The sensitivity and specificity to detect TCFA was also limited by VH-IVUS spatial resolution.

\section{FEASIBILITY OF COMBINED CARDIOVASCULAR MRI AND PERCUTANEOUS CORONARY INTERVENTION IN A HYBRID LABORATORY}

doi:10.1136/heartjnl-2012-301877b.25

${ }^{1} \mathrm{G}$ Morton, ${ }^{*}{ }^{1} \mathrm{~S}$ Hussain, ${ }^{1} \mathrm{~K}$ De Silva, ${ }^{1} \mathrm{~A}$ Dahl, ${ }^{2} \mathrm{~S}$ Redwood, ${ }^{1} \mathrm{~S}$ Plein, ${ }^{1} \mathrm{D}$ Perera, ${ }^{1}$ E Nagel. 'King's College London, UK; ' ${ }^{\prime}$ Guys and St Thomas' NHS Foundation Trust, UK

Background The relationship between anatomy and associated pathophysiology in coronary artery disease (CAD) is complex and 


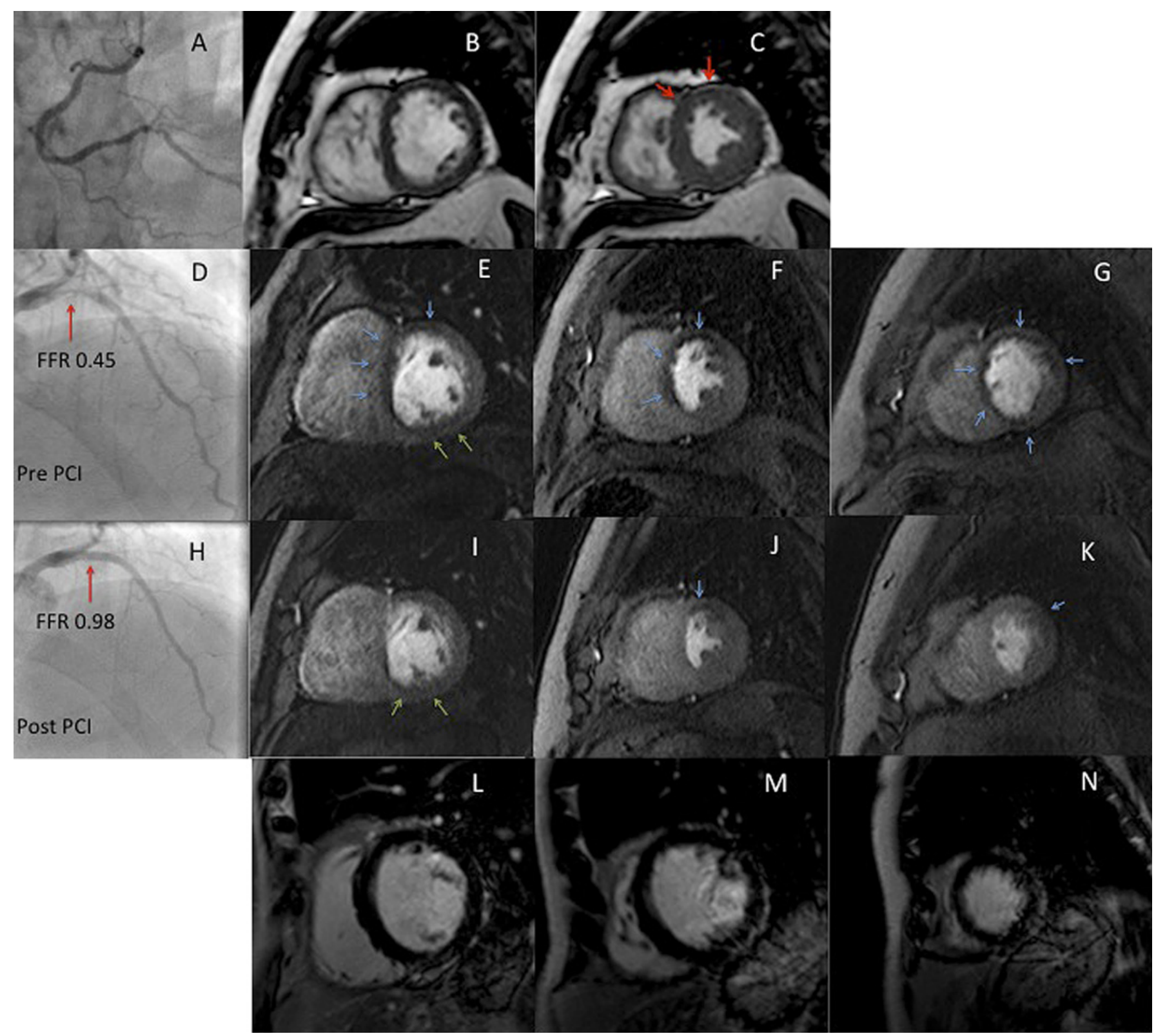

Abstract 025 Figure 1

incompletely understood yet is important for patient management. This information cannot be comprehensively provided by a single investigative modality. A hybrid x-ray and MRI (XMR) laboratory can potentially overcome this limitation. However, the feasibility of combined invasive and non-invasive studies and percutaneous coronary intervention (PCI) in an XMR laboratory is unknown.

Methods 10 patients with angina scheduled for coronary angiography or PCI underwent combined procedures an XMR laboratory. 3T Cardiovascular Magnetic Resonance (CMR) exams included serial high-resolution perfusion, functional and scar imaging. Invasive procedures included diagnostic coronary angiography, PCI and fractional flow reserve (FFR) measurements pre and post PCI.

Results Four females and 6 males with mean age 73 (range 51-86) were included. All procedures were completed and well tolerated without complication. Mean study duration was $117 \mathrm{~min}$ (range 36-208). The procedures and outcomes are summarised in
Abstract 025 table 1. Eight patients underwent both CMR and invasive studies. Six patients had single vessel PCI. FFR and stress perfusion imaging were both performed in 14 coronary territories (4 post PCI). Management was guided by functional information in eight patients. An example case is shown in Abstract 025 figure 1. End-diastolic (B) and end-systolic (C) frames from the short axis cine demonstrate an anterior/anteroseptal wall motion abnormality. Stress perfusion imaging pre PCI demonstrated a severe perfusion defect in the LAD territory from base to apex (E-G; blue arrows) and a defect in the RCA territory (E; green arrows). There were corresponding severe lesions in the proximal LAD with an FFR of 0.45 (D) and RCA (A). Following PCI to the LAD FFR increased to 0.98 and stress perfusion was significantly improved (I-K). The RCA territory defect remained (I; green arrows) but there was also persistent hypoperfusion in the mid anterior slice (J; blue arrow) and apical lateral wall (K; blue arrow) despite the absence of scar on late gadolinium enhancement imaging $(\mathrm{L}-\mathrm{N})$. 
Abstract 025 Table 1

\begin{tabular}{|c|c|c|c|c|c|c|c|}
\hline $\begin{array}{l}\text { Patient } \\
\text { number }\end{array}$ & Age & Sex & $\begin{array}{l}\text { Coronary } \\
\text { disease }\end{array}$ & $\begin{array}{l}\text { CMR stress } \\
\text { perfusion }\end{array}$ & $\begin{array}{l}\text { FFR pre } \\
\text { PCI }\end{array}$ & $\begin{array}{l}\text { FFR post } \\
\text { PCI }\end{array}$ & Outcome \\
\hline 1 & 65 & $\mathrm{~F}$ & Minor & $\mathrm{N} / \mathrm{A}$ & $\mathrm{N} / \mathrm{A}$ & & Medical \\
\hline 2 & 77 & $M$ & $\begin{array}{l}\mathrm{LAD} \\
\mathrm{Cx}\end{array}$ & $\begin{array}{l}\text { Negative } \\
\text { Negative }\end{array}$ & $\mathrm{N} / \mathrm{A}$ & & Medical \\
\hline 3 & 71 & $M$ & $\mathrm{RCA}$ & $\mathrm{N} / \mathrm{A}$ & & & PCI RCA \\
\hline 4 & 76 & $\mathrm{~F}$ & LAD & Positive & 0.68 & & PCI LAD \\
\hline 5 & 79 & $\mathrm{M}$ & LAD & Positive & 0.38 & 0.92 & PCI LAD \\
\hline 6 & 79 & $\mathrm{~F}$ & $\begin{array}{l}\text { LAD } \\
C x\end{array}$ & $\begin{array}{l}\text { Negative } \\
\text { Negative }\end{array}$ & $\begin{array}{l}0.73 \\
0.90\end{array}$ & 0.83 & PCI LAD \\
\hline 7 & 86 & $\mathrm{~F}$ & LAD & Scar & $\mathrm{N} / \mathrm{A}$ & & Medical \\
\hline 8 & 61 & $M$ & $\begin{array}{l}\mathrm{Cx} \\
\mathrm{RCA}\end{array}$ & $\begin{array}{l}\text { Positive } \\
\text { Negative }\end{array}$ & $\begin{array}{l}0.55 \\
0.29\end{array}$ & 0.95 & $\mathrm{PCl} C \mathrm{x}$ \\
\hline 9 & 75 & $\mathrm{M}$ & $\begin{array}{l}\text { LAD } \\
\text { Cx } \\
\text { RCA }\end{array}$ & $\begin{array}{l}\text { Negative } \\
\text { Negative } \\
\text { Negative }\end{array}$ & $\begin{array}{l}0.83 \\
0.91\end{array}$ & & Medical \\
\hline 10 & 51 & $\mathrm{M}$ & $\begin{array}{l}\text { LAD } \\
\text { Cx } \\
\text { RCA }\end{array}$ & $\begin{array}{l}\text { Positive } \\
\text { Negative } \\
\text { Positive }\end{array}$ & $\begin{array}{l}0.45 \\
0.96\end{array}$ & 0.98 & PCI LAD \\
\hline
\end{tabular}

$\mathrm{Cx}$, circumflex artery; LAD, left anterior descending artery; RCA, right coronary artery.

Conclusions Combined CMR and interventional coronary procedures are feasible and well tolerated in an XMR laboratory. This setup has exciting research and clinical applications which should improve knowledge and management of coronary artery disease.

\section{LEFT BUNDLE BRANCH BLOCK AS AN ACTIVATION CRITERION FOR PRIMARY PERCUTANEOUS CORONARY INTERVENTION: WHERE IS THE EVIDENCE?}

doi:10.1136/heartjnl-2012-301877b.26

A J Brown, ${ }^{*}$ M Malone-Lee, L M McCormick, S P Hoole, P M Schofield, N E J West. Papworth Hospital, UK

Background The activation criteria for primary percutaneous coronary intervention (PPCI) includes chest pain in association with either ST-segment elevation (STEMI) or new-onset left bundle branch block (LBBB) on the ECG. However, defining LBBB as new is challenging acutely and the poor specificity of indeterminate chronicity $\mathrm{LBBB}$ may result in unnecessary PPCI activations. Published data are conflicting with regard to the utility of LBBB as a triage criterion for PPCI and subsequent outcomes are undefined.

Methods Consecutive patients attending a single UK tertiary centre for presumed PPCI between September 2008 and December 2010 were included $(n=1328)$. The activation ECG was obtained from the hospital PPCI database, as were demographic data. Outcome data were obtained from notes and national databases. MACE was defined as a composite of mortality and unplanned revascularisation. Two interventionists blinded to patient outcome reviewed the angiographic images and adjudicated if the activation was appropriate.

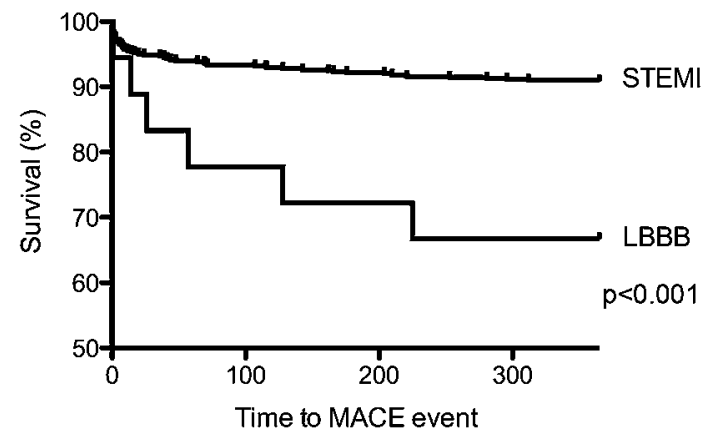

Abstract 026 Figure 1
Results Chest pain with LBBB (LBBB-activation) occurred in 88 patients $(6.6 \%)$ of the PPCI cohort. Comparing LBBB-activations to those with STEMI demonstrated that LBBB-activations were older (mean age $70.3 \pm 12.4$ vs $64.6 \pm 13.4$ years; $\mathrm{p}<0.001$ ) and less likely to be male $(67.0 \%$ vs $76.8 \% ; p=0.004)$. Otherwise, baseline demographics were similar. Eighteen (20.5\%) patients with LBBB had an acute thrombotic coronary occlusion confirmed at angiography and received $\mathrm{PPCI}$. The final adjudicated diagnoses for $\mathrm{LBBB}$-activations were acute coronary syndrome (ACS) (39.8\%), non-ACS cardiac $(28.4 \%)$ and non-cardiac (31.8\%). A history of previous MI $(p=0.002)$ and presence of cardiogenic shock on arrival $(p=0.04)$ were more prevalent in the appropriate LBBB-activations. One-year mortality and MACE were higher for appropriate LBBB-activations than the STEMI activations (27.8\% vs $7.9 \%$; $=0.002$ (Abstract 026 figure 1) and $33.3 \%$ vs $9.1 \%$; $<<0.001$ respectively).

Conclusions Less than half of LBBB-activations had an ACS and, of these, only half had a thrombotic coronary occlusion requiring PPCI. However, LBBB-activations have a significantly worse prognosis and merit urgent referral. Enhanced triage methods are required to correctly identify acute MI requiring PPCI in those with LBBB.

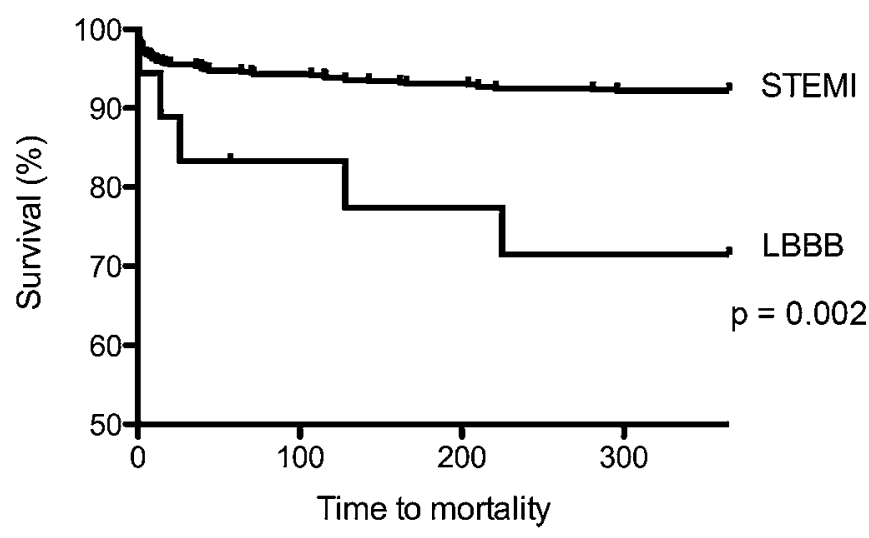

Abstract 026 Figure 2

\section{PERCUTANEOUS CORONARY INTERVENTION IN OCTOGENARIANS: RESULTS FROM A HIGH VOLUME CENTRE}

doi:10.1136/heartjnl-2012-301877b.27

R Showkathali, ${ }^{*}$ E Boston-Griffiths, H Patel, A Ramoutar, J Davies, A Kabir, R Gamma, R Jagathesan, J Sayer, G Clesham, P Kelly, R Aggarwal. The Essex Cardiothoracic Centre, Essex, UK

Aims Octogenarians constitute a fast growing group of patients referred for percutaneous coronary intervention (PCI) for stable angina and acute coronary syndromes (ACS). However, there are limited outcome data for PCI in this group. We evaluated the outcome of PCI in patients aged $\geq 80$ years and compared them with younger patients treated in our centre.

Methods We analysed all patients aged $\geq 80$ years who underwent PCI in our unit between September 2009 and December 2010. Prospectively entered data were obtained from our dedicated cardiac service database system (Philips CVIS). Mortality data were obtained from the summary care record (SCR) database. Follow-up data were obtained from patients' respective district general hospitals and general practitioners' medical records. We defined major bleeding as anyone requiring at-least one unit of red cell transfusion. Results Of the 2931 patients who underwent PCI in our unit during the study period, $401(13.7 \%)$ patients were $\geq 80$ years of age. Out of this $163(40.6 \%)$ had primary PCI (PPCI) for STEMI, 120 (29.9\%) 